\title{
Preliminary structural assessment of the HELIAS 5-B breeding blanket
}

\author{
G. Bongioví $^{1}$, A. Häußler ${ }^{1}$, P. Arena ${ }^{2}$ and the W7-X team \\ ${ }^{1}$ Karlsruhe Institute of Technology, Germany \\ 2Università di Palermo, Italy
}

The European Roadmap to the realisation of fusion energy considers the stellarator concept as a possible long-term alternative to a tokamak fusion power plant. To this purpose a pivotal issue is the design of a HELIcal-axis Advanced Stellarator (HELIAS) machine equipped with a tritium Breeding Blanket (BB). Therefore, within the framework of EUROfusion Work Package S2 R\&D activity, a research campaign has been launched at KIT. The scope of the research, focussed on the HELIAS 5-B machine, has been the determination of a preliminary BB segmentation scheme able to ensure, under the assumed loading conditions, that no overlapping may occur among the BB neighbouring regions. To this purpose, the Helium-Cooled Pebble Bed (HCPB) and the Water-Cooled Lithium Lead (WCLL) BB concepts, presently considered for the DEMO tokamak fusion reactor, have been taken into account. The obtained results are herewith presented and critically discussed.
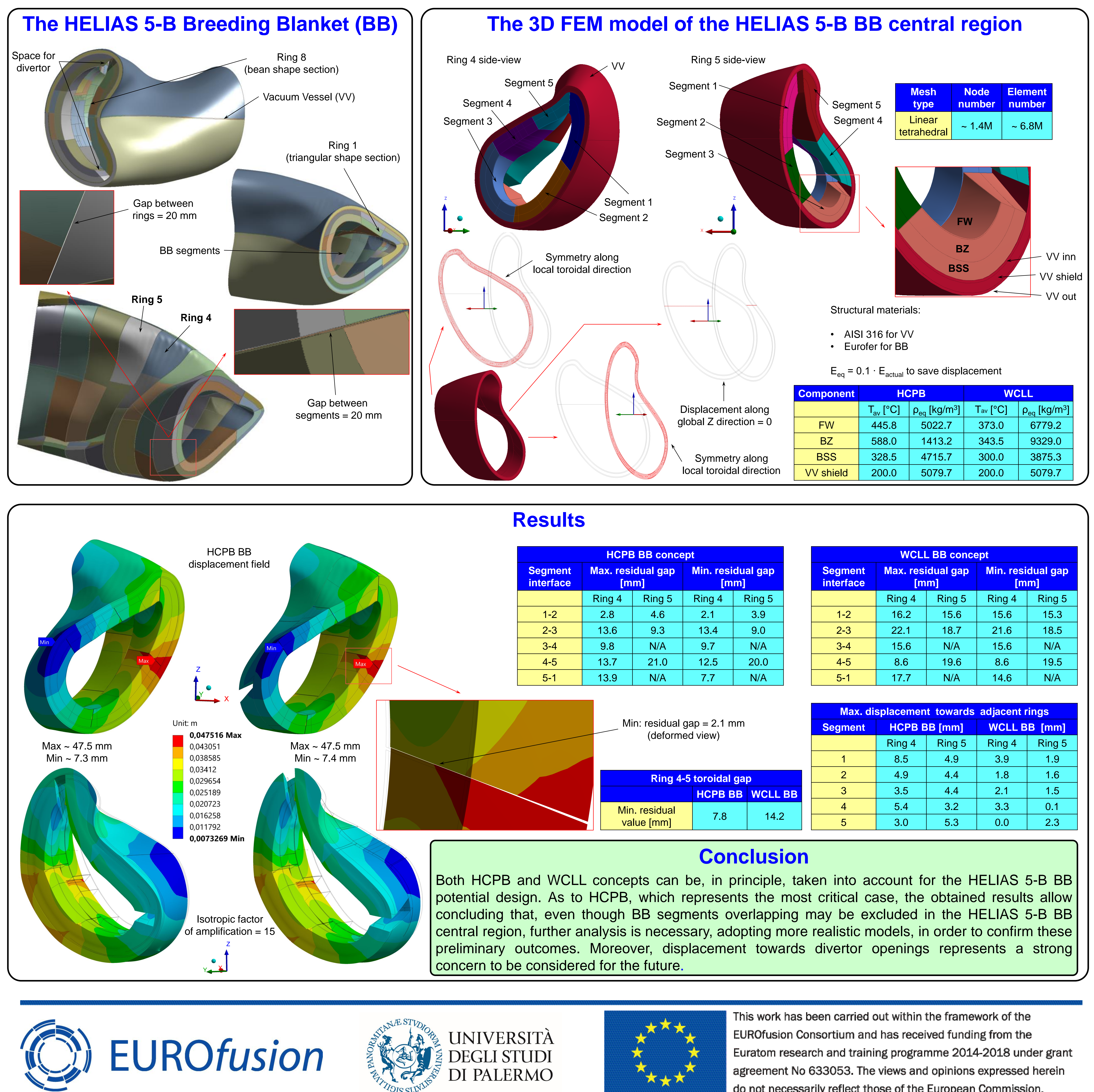

UNIVERSITÀ

DEGLI STUDI

DI PALERMO

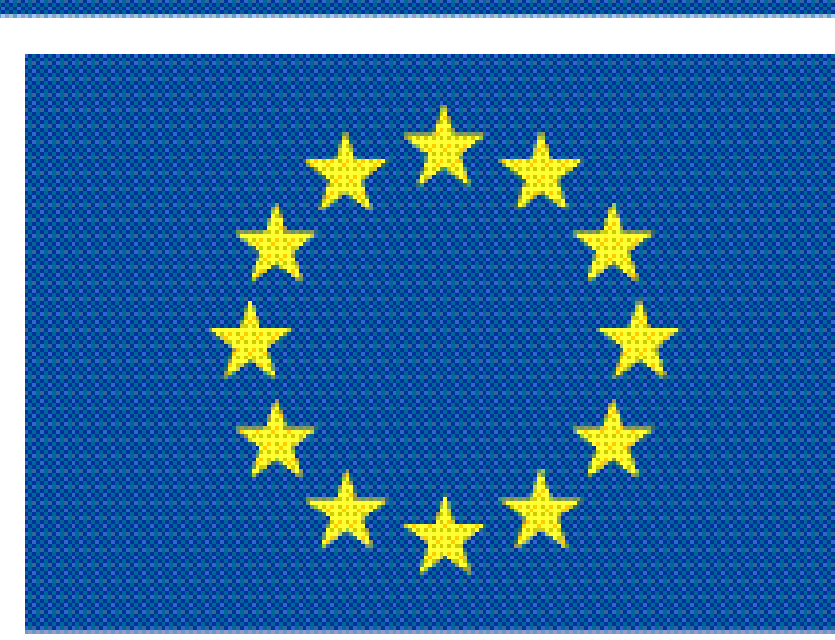

This work has been carried out within the framework of the EUROfusion Consortium and has received funding from the Euratom research and training programme 2014-2018 under grant agreement № 633053. The views and opinions expressed herein do not necessarily reflect those of the European Commission. 